Article

\title{
Evaluation of High-Temperature Performance of Asphalt Mixtures Based on Climatic Conditions
}

\author{
Yan $\mathrm{Mu}^{1}{ }^{1}$, Zhen Fu ${ }^{1}{ }^{*}$, Jian Liu ${ }^{2}$, Chen $\mathrm{Li}^{2}$, Wenhao Dong ${ }^{2}$ and Jiasheng Dai ${ }^{2}$ \\ 1 School of Material and Science Engineering, Chang'an University, Xi'an 710064,China; my_bj_2008@126.com \\ 2 Key Laboratory Special Area Highway Engineering of Ministry of Education, Chang'an University, \\ Xi'an 710064, China; liujian14588@126.com (J.L.); lixychen@126.com (C.L.); dongwenhao@chd.edu.cn (W.D.); \\ daijiasheng@163.com (J.D.) \\ * Correspondence: zhenfu@chd.edu.cn
}

Received: 11 May 2020; Accepted: 28 May 2020; Published: 31 May 2020

check for updates

\begin{abstract}
The dynamic stability of a rutting test does not optimally reflect the high-temperature stability of asphalt mixtures. In this study, a rutting test was performed over a long duration $(4 \mathrm{~h})$ at different temperatures $\left(40,50,60,70^{\circ} \mathrm{C}\right)$ for three asphalt mixtures, namely, matrix AC-16, SMA-16, and modified AC-16 asphalt mixtures. Subsequently, the temperature rutting rate was obtained after considering the annual temperature conditions of Guangdong and Beijing in China. Because the conditions of the rutting test were different from that of the actual pavement, the rut depth was calculated using a modified temperature rutting rate. This modification considered four factors: wheel trace distribution, temperature, pavement thickness, and loading rate. The calculation of the temperature rutting rate considered the climatic conditions and utilized the rutting deformation data from hour 1-4 of the rutting tests, during which the asphalt mixture was in a stable creep period. Thus, the high-temperature stability of the asphalt mixture was reflected more scientifically by the temperature rutting rate than the dynamic stability. The high-temperature rut-resistance of the asphalt mixture was found to improve significantly after the introduction of two additives (anti-rutting agent and lignin fiber). The modified formula for rut depth can realistically predict the annual rutting depth for three asphalt mixtures in a one-way driving pavement.
\end{abstract}

Keywords: highway engineering; asphalt mixture; high-temperature performance; temperature rutting rate; climatic condition

\section{Introduction}

Rutting damage, occurring at high temperatures, has become the main form of pavement damage [1]. Several tests are used globally in order to evaluate the high-temperature performance of asphalt mixtures, including the Marshall test, creep test, and rutting test. Among these, the rutting test is most widely used because it can reasonably simulate the actual state of the pavement caused by driving. In addition, several indexes characterizing the high-temperature performance of asphalt mixtures are also obtained based on the rutting test.

Several researchers have investigated the selection of a high-temperature performance index for asphalt mixtures. Anderson [2] found that the high-temperature performance of asphalt mixtures can be studied by investigating their rotary compaction performance; Zheng et al., [3] adopted the dynamic stability of whole process (DSWP) to evaluate the anti-rut performance of the asphalt mixture. Subsequently, he compared it with the current dynamic stability (DS) and highlighted the deficiency of dynamic stability. Kim et al. [4] studied a new static loading program, and found that the test results are highly consistent with those of rutting test and asphalt pavement analyzer (APA), which can be used to evaluate the high-temperature performance of asphalt mixture; Ziari et al., [5] proposed that 
the rut depth can be predicted using the model of rotary shear stress and the slope of rotary compaction; Wen and Bhusal [6] proposed the indirect tensile test (IDT) to evaluate the high-temperature anti-rut performance of asphalt concrete; Ji et al., [7] proposed the relationship between shear strength and rut resistance, based on the existing rut judgment standard, and tried to determine the boundary standard; Hafeez and Kamal [8] believed that the relationship between creep flexibility and rut depth was linear; Laukkanen et al., [9] found that the test results of multi stress creep recovery (MSCR) test can be used to predict the high-temperature anti-rut performance of asphalt; Narayan et al., [10] proposed a non-linear viscoelastic model to represent the anti-rut ability and compared this index with other evaluation indexes and found that this simple model can be used to estimate the rut depth. Zhu et al., [11] suggested that the sensitivity of D-1 (the regression parameter in the Stephen Price model) can be used as an alternative indicator to assess the rutting resistance of mixtures, particularly for the polymer modified asphalt mixtures; Liu et al., [12] evaluated four types of asphalt concrete, with nanosized volcanic ash fine fillers, through the repeated-load plastic deformation test, using fiber Bragg grating (FBG) based equipment. The strain curve, in a steady cycle, was suggested as a quantitative indicator of the high-temperature anti-rut performance of asphalt mixtures. Dong et al., [13] found that both the dynamic modulus (DM) from the indirect tensile test (IDT) mode at $35^{\circ} \mathrm{C}$ and $10 \mathrm{~Hz}$ and the compound creep stiffness modulus (CCSM) were well correlated with the creep rate (CR) of hot-mix asphalt. Furthermore, compound average strain rate (CASR) exhibited the best potential for the prediction of actual field rutting. Khotbehsara et al., [14] found that the properties of the mixture can retain up to $72 \%$ at a temperature of $80{ }^{\circ} \mathrm{C}$. Ferdous et al. [15] observed that the glass transition temperature is critical for a mixture above which the properties degrade significantly. Liu et al., [16] conducted the repeated-load test to study the strain recovery characteristic of the asphalt mixture and proposed a new indicator, the ratio of residual strain (RRS), for the rutting resistance evaluation of all materials.

Although extensive research has been conducted on the high-temperature performance of asphalt mixtures, the dynamic stability obtained by the rutting test is primarily used as the high-temperature performance index of asphalt mixtures. However, the $1 \mathrm{~h}$ test does not accurately reflect the actual rut situation over a long period of rolling because the early high-temperature and anti-permanent deformation ability of the compacted asphalt mixtures are not reflected. Moreover, the changes in temperature are far more complex than those determined by conventional rutting tests, and the rutting test at only $60^{\circ} \mathrm{C}$ is unable to accurately simulate the pavement climate. Therefore, the dynamic stability does not accurately reflect the changes in pavement temperature or the actual long-term situation of the pavement being rolled.

In this study, a long-term $(4 \mathrm{~h})$ rutting test is performed at different temperatures $\left(40,50,60,70^{\circ} \mathrm{C}\right)$ for three asphalt mixtures: matrix AC-16 asphalt mixture, SMA-16 asphalt mixture, and modified AC-16 asphalt mixture. The relationship between the high-temperature performance of these asphalt mixtures and temperature was summarized. Beijing and Guangzhou were considered as examples because they have significant temperature differences. The local climatic conditions were studied in order to propose an improved scheme of dynamic stability—-the temperature rutting rate was proposed based on the local climatic conditions. Finally, the annual rutting depth of two places was calculated by considering the temperature rutting rate and the influence of wheel track distribution, temperature, thickness of asphalt layer, and loading rate. The results provide a better experimental evaluation method for main road performances of asphalt mixtures, and establish a scientific and reasonable evaluation index that can improve the technical performance of the asphalt pavement.

\section{Test Materials and Methods}

\subsection{Test Materials and Gradation}

Three typical asphalt mixtures were used in the test: matrix AC-16 asphalt mixture, SMA-16 asphalt mixture, and modified AC-16 asphalt mixture (hereinafter referred to as matrix AC-16, SMA-16, 
and modified AC-16, respectively). Furthermore, these three types of mixtures with obvious differences in material composition and application features can represent the traditional, new and modified types of mixtures, respectively [17]. Therefore, the research accounts for different types of mixtures and the results are more convincing. Shell 70\# asphalt is adopted in matrix AC-16 and modified AC-16 asphalt mixtures. Shell 70\# modified asphalt is used in SMA-16 asphalt mixtures. In addition, anti-rut agents and lignin fibers (lignin fibers can strengthen the low temperature crack resistance of mixture and improve the asphalt mixture pavement performance) are used as modifiers in modified AC-16. The aggregate and mineral powder used in SMA-16 is limestone and fine limestone flour, respectively. The main technical indexes of asphalt and modified asphalt are presented in Table 1 [18].

Table 1. Main technical indexes of asphalt.

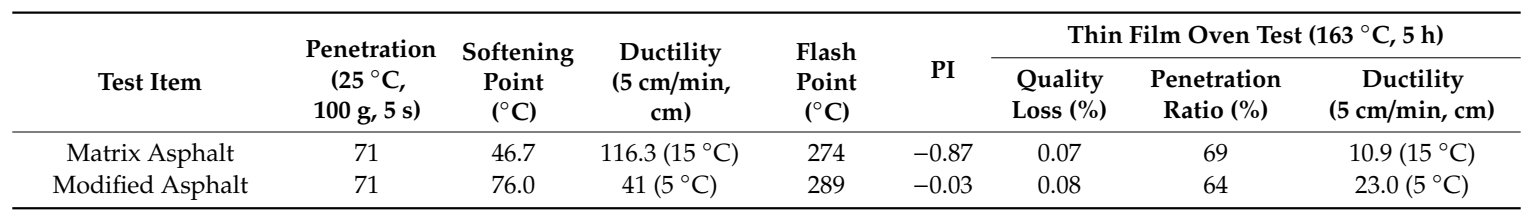

In order to the test results can be relatively controllable and comparable, the two mineral aggregate gradations AC-16 and SMA-16 were selected as mean values. The aggregate was represented by limestone, and shell 70\# asphalt and modified 70\# asphalt were used to represent the asphalt. Continuous gradation was adopted so that the concrete mixture had good workability and segregation was avoided. Thus, a dense concrete body was obtained after proper vibration. The two grades used are presented in Table 2.

Table 2. Gradation of asphalt mixture (unit: \%).

\begin{tabular}{cccccccccccc}
\hline \multirow{2}{*}{ Asphalt Mixture } & \multicolumn{8}{c}{ Aperture Size (mm) } \\
\cline { 2 - 10 } & $\mathbf{0 . 0 7 5}$ & $\mathbf{0 . 1 5}$ & $\mathbf{0 . 3}$ & $\mathbf{0 . 6}$ & $\mathbf{1 . 1 8}$ & $\mathbf{2 . 3 6}$ & $\mathbf{4 . 7 5}$ & $\mathbf{9 . 5}$ & $\mathbf{1 3 . 2}$ & $\mathbf{1 6}$ & $\mathbf{1 9}$ \\
\hline Matrix AC-16 & 6 & 9.5 & 12.6 & 15.5 & 24.5 & 32.0 & 48 & 70 & 91 & 95 & 100 \\
Modified AC-16 & 10 & 11.5 & 12.5 & 15.0 & 18.0 & 19.5 & 26 & 50 & 70 & 95 & 100 \\
SMA-16 & 10 &
\end{tabular}

\subsection{Preparation Method and Test Method}

\subsubsection{Determination of the Asphalt-Aggregate Ratio and Optimum Admixture Content}

The Marshall test was performed using matrix AC-16 under the conditions of $3.5 \%, 4 \%, 4.5 \%$, $5 \%$, and $5.5 \%$ asphalt-aggregate ratios. The optimum asphalt-aggregate ratio was determined as $4.3 \%$ according to the Marshall volume index. In a similar way, the optimum content of lignin fiber in SMA- 16 was set as $0.3 \%$ of the total mass of the asphalt mixture, and the optimum content of asphalt was $6.2 \%$. Two admixtures, including fiber, were added to the modified AC-16, which altered the composition proportion of the asphalt mixture. Before determining the asphalt-aggregate ratio of modified AC-16, the dry method was chosen as the mixing process of the mixture. The temperature of the mixture during the mixing process was in accordance with the requirements of Technical specifications for construction of highway asphalt pavements [19]. Then, the Marshall method was used to determine the asphalt content of the double mixture. The Marshall test was performed when the asphalt-aggregate ratio was $4 \%, 4.5 \%, 5 \%, 5.5 \%$, and $6 \%$, respectively, and the asphalt-aggregate ratio was determined as $5.1 \%$ according to the Marshall volume index.

\subsubsection{Preparation Method}

The test method of asphalt mixtures (wheel rolling method) was based on the requirements of the T 0703-2011 outlined in Specifications and test methods of bitumen and bituminous mixtures for highway engineering [19]. First, the mineral materials heated to $110{ }^{\circ} \mathrm{C}$ and the asphalt at $160{ }^{\circ} \mathrm{C}$ 
were mixed evenly by using the mixing pot in the road laboratory; then, the asphalt mixtures were poured into the rutting mold with dimensions of $300 \mathrm{~mm} \times 300 \mathrm{~mm} \times 50 \mathrm{~mm}$ and rut samples were manufactured by wheel rolling (see Figure 1); finally, the test samples were put together with the mold in a constant temperature box at $60{ }^{\circ} \mathrm{C}$ for at least $5 \mathrm{~h}$. Using this manufacture method, 12 matrix samples each of AC-16, SMA-16, and modified AC-16 were created with dimensions of $300 \mathrm{~mm} \times 300$ $\mathrm{mm} \times 50 \mathrm{~mm}$. In addition, 12 matrix samples each of SMA-16 and modified AC- 16 were produced with dimensions of $300 \mathrm{~mm} \times 300 \mathrm{~mm} \times 100 \mathrm{~mm}$.

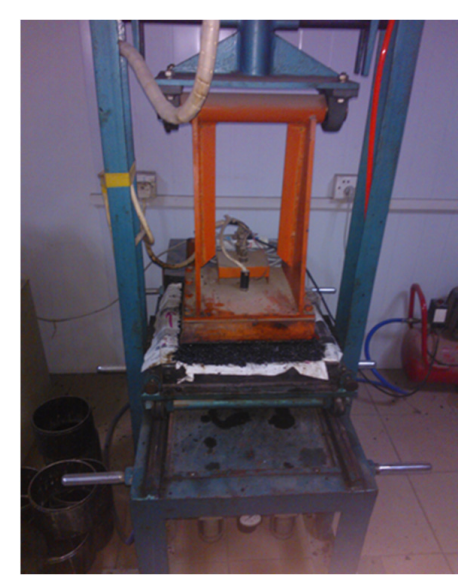

Figure 1. Rut sample manufactured by wheel rolling.

\subsubsection{Rutting Test}

The rut test instrument in this study was developed based on the Japanese prototype (see Figure 2). It has an outer diameter of the steel wheel of $200 \mathrm{~mm}$, a wheel width of $50 \mathrm{~mm}$ and a wheel pressure of $0.7 \mathrm{MPa}$. The rut test instrument was used to perform the rutting test, over a long duration of $(4 \mathrm{~h})$, at different temperatures $\left(40,50,60,70^{\circ} \mathrm{C}\right)$ for two types of samples, having a thickness of 50 and $100 \mathrm{~mm}$. It enabled us to decide the starting time of the stable creep period of the mixture and obtain the rutting factor and rutting rate of the mixture according to the rutting test. The main procedure of the rutting test was as follows: firstly, the rutting plate which was preheated for $5 \mathrm{~h}$ in $60{ }^{\circ} \mathrm{C}$ air bath environment was placed under the rubber test wheel; then, the test wheel was lowered and 0.7 MPa pressure was generated on the upper surface of the rutting plate; finally, the equipment was started and the test wheel drove repeatedly on the same track (the direction was the same as the forming direction) to form a certain depth of rutting. The two sample sizes were divided into three groups, and parallel tests were conducted on two of the groups. The results of the rutting test conducted with a sample having dimensions $300 \mathrm{~mm} \times 300 \mathrm{~mm} \times 100 \mathrm{~mm}$ are detailed in Section 3.5.3.

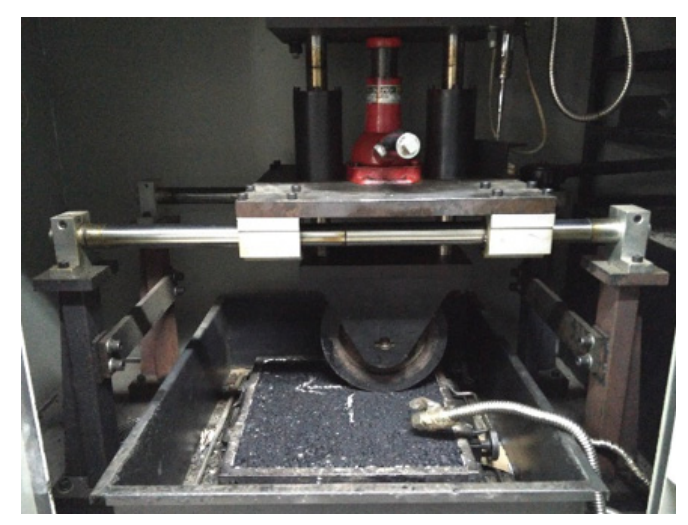

Figure 2. Rut test instrument. 


\section{Test Results and Analysis}

In this section, the rutting factor, rutting rate, temperature rutting rate, and rut depth are discussed based on the test results of the $50 \mathrm{~mm}$ thick rut test instrument. The rutting factor $(\mathrm{mm} / \mathrm{time})$ refers to the linear relationship between the rut depth and time when the mixture enters the stable period after long-term rolling under the standard axle load. The rutting rate $(\mathrm{mm} / \mathrm{load}$ times) denotes the relationship between the deformation and loading times under the same condition. The temperature rutting rate ( $\mathrm{mm} / \mathrm{load}$ times) represents a correction of the rutting rate, after accounting for the local temperature conditions. Finally, the temperature rutting rate was combined with the local traffic load times of different traffic levels, and four factors were considered, including wheel track distribution, temperature, layer thickness, and loading rate. This was used to calculate the annual rut depth and safe service life of the asphalt mixtures, so as to evaluate whether the temperature rutting rate could be used as the high temperature evaluation index of the asphalt mixture.

\subsection{Temperature and Rutting Rate}

Figure 3 depicts the test samples prior and post rutting test, respectively. It can be seen that the surface of test samples had obvious wheel tracks after rutting test.

\section{(a)}

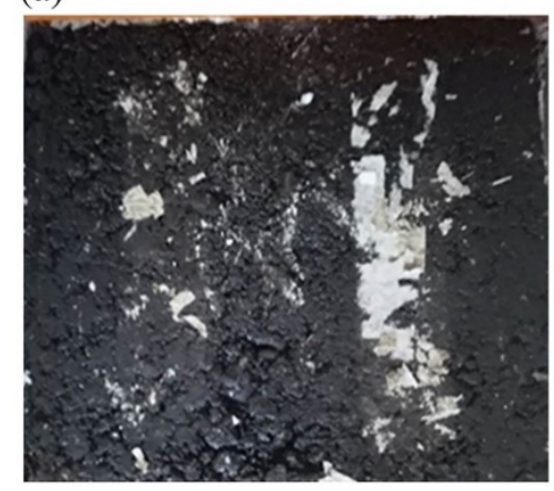

(b)

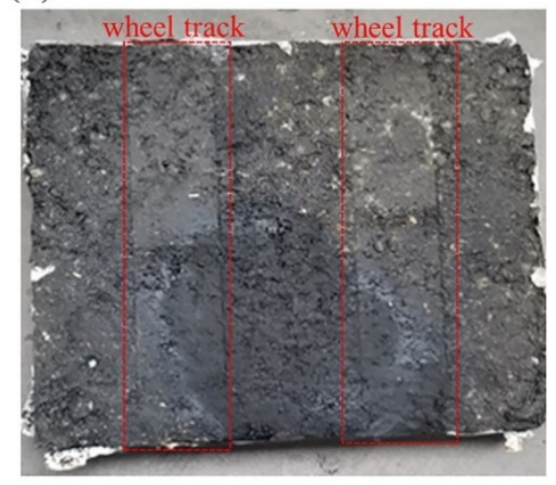

Figure 3. The test samples (a) prior to and (b) post rutting test.

The relationship between the rut depth and time of asphalt mixtures at different temperatures is illustrated in Figure 4. It can be seen that the deformation rate of the mixtures stabilized after being rolled for approximately $1 \mathrm{~h}$ by the rut test instrument, and the deformation of the asphalt mixtures was proportional to the time. As the temperature increased, the deformation became larger. Under the effect of high temperature, due to the softening and volume expansion of asphalt, the stability of asphalt concrete decreased sharply with an increase in temperature, and the structural strength also decreased. Therefore, as the temperature increased, the stiffness modulus of the asphalt mixture decreased, and the anti-rut ability became smaller. The rutting factor was the slope of the deformation-time curves. Figure 5 displays the rutting factors of the three mixtures at different temperatures; it is evident that the rutting factor increased with temperature. 

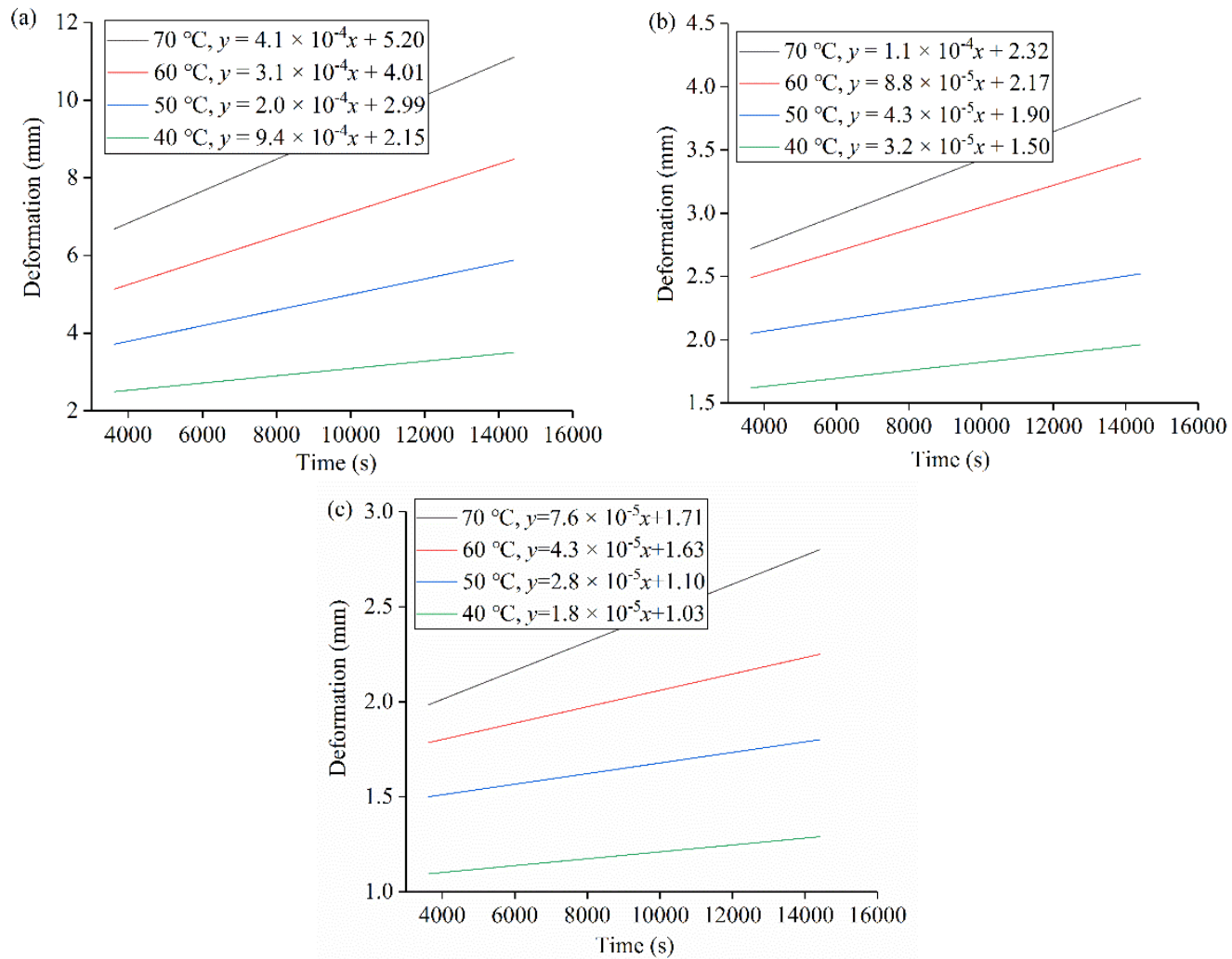

Figure 4. The relationship between deformation and loading time of the three asphalt mixtures:

(a) matrix AC-16; (b) SMA-16; (c) modified AC-16.

In this study, because the temperature rutting ratio is used to characterize the high-temperature performance of the asphalt mixture, the rutting factor should be converted to the rutting ratio. The load rate of the rutting test was 42 times per minute. Thus, the linear relationship between the asphalt mixture deformation and loading times is expressed as follows:

$$
\delta=\frac{60}{42} a
$$

where $\delta$ represents the rutting rate and $a$ denotes the rutting factor.

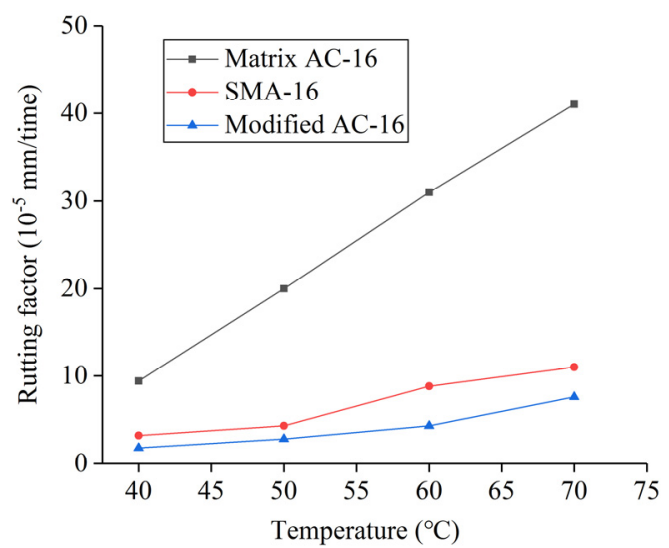

Figure 5. Variations of rutting factors of the three asphalt mixtures with temperature.

The fitting curves of temperature and rutting rate of the three asphalt mixtures are depicted in Figure 6 , based on the rutting test results, and their determination coefficients were $0.9667,0.9450$ and 0.9945 , respectively. The rutting rate of the three asphalt mixtures exhibited an exponential growth 
trend with increasing temperature. As the temperature increased, there was a greater increase in the rutting rate. The rutting rate of the mixture at higher temperatures (pavement temperature $=$ $70{ }^{\circ} \mathrm{C}$ ) was 10 times larger than that at low temperatures (pavement temperature $<30^{\circ} \mathrm{C}$ ). When the temperature was lower than $30^{\circ} \mathrm{C}$, the rutting rate of AC-16 and SMA-16 was significantly small. It can be seen that rutting was mainly formed at high temperatures. At the same test temperature, the asphalt mixtures having the minimum and maximum rutting rate were modified AC-16 and matrix AC-16, respectively. Thus, it can be concluded that the addition of an anti-rutting agent significantly improved the high-temperature anti rutting performance of the asphalt mixture, which was an effective way to improve the high-temperature performance of materials. In addition, the performance of the asphalt mixture with different gradations and additives was vastly different at high temperatures, while at low temperatures, it had a similar anti-rut ability.

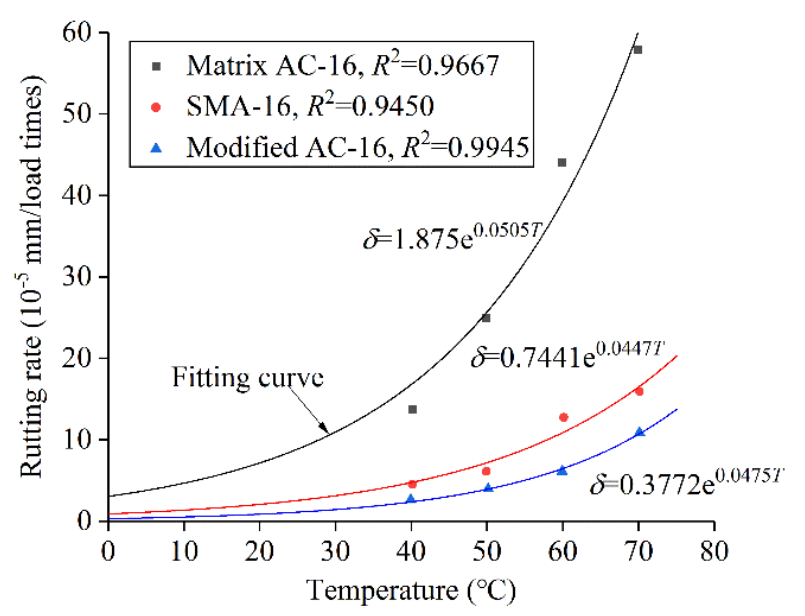

Figure 6. Fitting curves of temperature and rutting rate of the three asphalt mixtures.

\subsection{Combination of Temperature and Rutting Rate in Different Regions}

In the high-temperature seasons, the asphalt pavement "softens". Under the repeated action of load stress, the plastic deformation of the asphalt pavement gradually accumulates, resulting in the existence of rutting, which can reduce the pavement smoothness. As the temperature increases, the stiffness of the asphalt pavement decreases, ranging from the hard and brittle solid at low temperatures, viscoelastic body at normal temperatures, and softening at high temperatures to a flowing state. The strength of the asphalt mixture is significantly influenced by temperature, and rutting mainly occurs in the high-temperature seasons. In order to accurately evaluate the ability of the asphalt mixture to resist rutting deformation at high-temperatures, this study adopts the daily maximum pavement temperature as the average daily temperature to simulate the maximum rut depth on the asphalt pavement.

Guangdong and Beijing of China were considered as examples, as they have large differences in climate. The distribution of the daily maximum air temperatures in these two places during 2006 was analyzed (there were no unusual weather changes throughout the year, thereby accurately reflecting the climate distribution in Beijing and Guangzhou). The research results of the SHRP asphalt mixture were used to transform the corresponding climatic temperatures into the surface temperature of the pavement and the temperature $20 \mathrm{~mm}$ below the pavement surface (Figure 7). The impact of the air temperature on the performance of the asphalt pavement was analyzed.

The SHRP-A-648A report [20] suggested that at high temperatures, the surface temperature of the pavement, $T_{\text {surf }}$, was determined by the hot air flow on the pavement surface, which was related to multiple factors. Based on a theoretical analysis, the transformation of $T_{\text {surf }}$ and air temperature $T_{\text {air }}$ can be established through latitude Lat as follows:

$$
T_{\text {surf }}=T_{\text {air }}-0.00618 \text { Lat }^{2}+0.2289 \text { Lat }+22.4
$$




$$
T_{20 m m}=\left(T_{\text {surf }}+17.78\right) \times 0.9545-17.78
$$

where the Lat of Beijing and Guangzhou are chosen as $40^{\circ}$ and $23^{\circ}$, respectively.

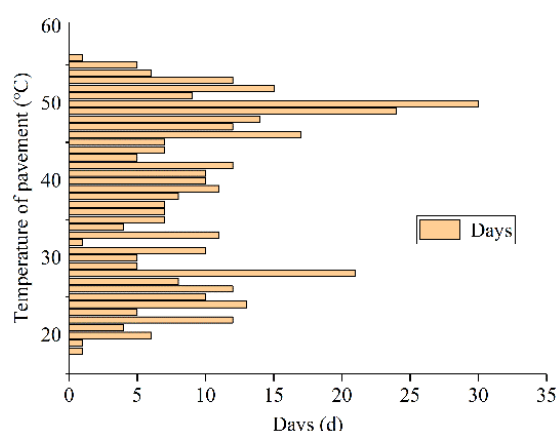

(a)

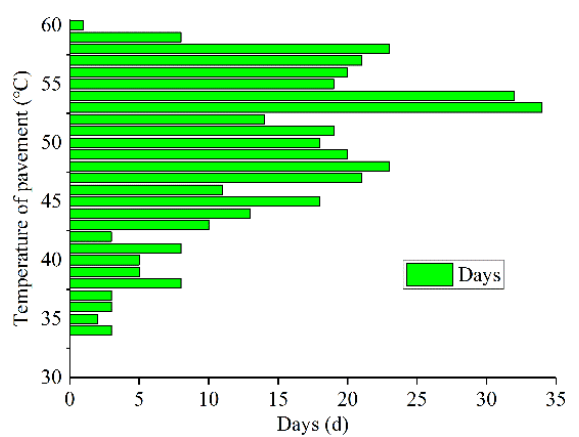

(b)

Figure 7. Distribution of daily maximum pavement temperatures in Beijing and Guangzhou in 2006. (a) Beijing, (b) Guangzhou.

A combination of the data in Figures 6 and 7 enables us to obtain the annual temperature-modified rutting rate as follows:

$$
\delta_{T}=\frac{\sum\left(\delta \times T_{20 m m} \times n_{T}\right)}{365} a
$$

where $\delta_{T}$ represents the rutting rate after accounting for the temperature and $n_{T}$ denotes the duration of a certain pavement temperature.

The temperature rutting rates in Beijing and Guangzhou can be obtained by using the data in Figures 5 and 7 and Equation (5). The results are presented in Table 3. The temperature rutting rate of Guangzhou is greater than that of Beijing for the same mixture, when the temperature rutting rate is used to evaluate the high-temperature performance of the asphalt mixture. Thus, significant differences are exhibited in the final rut depth of the two regions, under the same driving conditions. This is because the temperatures in these regions are vastly different, and the rutting ratio is known to increase exponentially with temperature at high temperatures. Guangzhou has high temperatures for a longer duration, so rut formation for the same asphalt mixture is likelier in Guangzhou than in Beijing.

Table 3. Temperature rutting rates of asphalt mixture in Beijing and Guangzhou (unit: $10^{-5} \mathrm{~mm} / \mathrm{load}$ times).

\begin{tabular}{ccc}
\hline Asphalt Mixture & Beijing & Guangzhou \\
\hline Matrix AC-16 & 15.45 & 34.51 \\
SMA-16 & 4.75 & 10.19 \\
Modified AC-16 & 2.67 & 5.81 \\
\hline
\end{tabular}

\subsection{Prediction of Annual Rut Depth}

This study considers the heavy traffic loading condition as a reference. Based on Specifications for design of highway asphalt pavement (JTGD50-2006), the design life of a special traffic pavement is 20 years. Assuming that the total loading times per year is the same, the average standard axle load per year is 1.5 million times. Considering that the strain rate of asphalt mixture during the stable creep period is basically unchanged [21], Equation (5) is used to calculate the daily rut depth of the asphalt mixture during this period. The annual rut depth is obtained from this data (see Table 4).

$$
\varepsilon=\delta_{T} \times c+b
$$

where $\varepsilon$ represents the rut depth, $c$ denotes the loading axle, and $b$ denotes the rut depth prior to the stable creep period. 
Table 4. Prediction of annual rut depth in special traffic areas of Beijing and Guangzhou (unit: mm).

\begin{tabular}{ccc}
\hline Asphalt Mixture & Beijing & Guangzhou \\
\hline Matrix AC-16 & 231.72 & 368.04 \\
SMA-16 & 71.31 & 108.27 \\
Modified AC-16 & 37.76 & 57.79 \\
\hline
\end{tabular}

It can be seen from Table 4 that under heavy traffic loading conditions, the annual rut depth generated by three different asphalt mixtures in Beijing was significantly smaller than that in Guangzhou. The rut depth in Guangzhou was approximately double that in Beijing. This indicates that the continuous high air temperatures in Guangzhou caused the asphalt concrete there to be tested more severely. Therefore, Guangzhou requires an asphalt mixture with a better high- temperature performance. The asphalt mixtures that produced the maximum and minimum annual rut depths were matrix AC-16 and modified AC-16, respectively. Thus, it can be concluded that the addition of an anti-rutting agent is an effective method to improve the high temperature properties of materials, thereby significantly improving the anti-rutting performance of the asphalt mixture at high temperatures.

\subsection{Comparison of Evaluation Indexes}

The results of the rutting test demonstrated that the first hour of the test is the creep transition period of the asphalt mixture. However, the influence of rut depth generated during the first hour was not considered when using the temperature rutting rate to evaluate the anti-rutting performance of the asphalt mixtures at high temperatures. To determine the influence of the rut depth during the first hour on the annual rut depth, a rutting test was conducted on three asphalt mixtures over a long period $(4 \mathrm{~h})$. The rut depths produced by the mixtures at $45 \mathrm{~min}$ and $1 \mathrm{~h}$ and the annual rut depth of Beijing and Guangzhou, which was calculated using a temperature rutting rate, are presented in Table 5.

Table 5. Rut depths at $45 \mathrm{~min}$ and $1 \mathrm{~h}$ of rutting test and total annual predicted rut depth.

\begin{tabular}{|c|c|c|c|c|c|}
\hline \multirow{2}{*}{$\begin{array}{l}\text { Asphalt } \\
\text { Mixture }\end{array}$} & \multicolumn{2}{|c|}{ Rutting Test at $60^{\circ} \mathrm{C}$} & \multirow{2}{*}{$\begin{array}{l}\text { Ratio of Rut } \\
\text { Depths at } 45 \\
\text { min to } 1 \mathrm{~h}(\%)\end{array}$} & \multirow{2}{*}{$\begin{array}{c}\text { Prediction of } \\
\text { Annual Rut Depth } \\
\text { in Beijing (mm) }\end{array}$} & \multirow{2}{*}{$\begin{array}{c}\text { Ratio of Annual } \\
\text { and } 1 \text { h Rut } \\
\text { Depths (\%) }\end{array}$} \\
\hline & $\begin{array}{l}\text { Rut Depths at } \\
45 \mathrm{~min}(\mathrm{~mm})\end{array}$ & $\begin{array}{c}\text { Rut Depths at } \\
1 \mathrm{~h}(\mathrm{~mm})\end{array}$ & & & \\
\hline \multirow{3}{*}{ Matrix AC-16 } & 3.541 & 3.985 & 88.9 & \multirow{3}{*}{231.72} & 1.72 \\
\hline & 5.393 & 6.071 & 88.8 & & 2.62 \\
\hline & 4.862 & 5.533 & 87.9 & & 2.39 \\
\hline \multirow{3}{*}{ SMA-16 } & 2.233 & 2.346 & 95.2 & \multirow{3}{*}{71.31} & 3.29 \\
\hline & 2.310 & 2.459 & 93.9 & & 3.45 \\
\hline & 2.540 & 2.894 & 87.8 & & 4.06 \\
\hline \multirow{3}{*}{$\begin{array}{l}\text { Modified } \\
\text { AC-16 }\end{array}$} & 1.137 & 1.227 & 92.7 & \multirow{3}{*}{37.76} & 3.25 \\
\hline & 1.831 & 1.887 & 97.0 & & 5.00 \\
\hline & 1.993 & 2.092 & 95.3 & & 5.54 \\
\hline
\end{tabular}

It can be seen that the dynamic stability index of the rutting test only considered the relationship between the deformation of the material and the loading times within $15 \mathrm{~min}$ after rolling, and neglects the influence of the deformation before $45 \mathrm{~min}$. It was found that the deformation during the first 45 min could account for most of the total deformation in $1 \mathrm{~h}$, which was more than $90 \%$. Therefore, this study suggests that the asphalt mixture did not completely enter the stable creep period within 45 min to $1 \mathrm{~h}$, and the dynamic stability was defective in reflecting the anti-rutting ability of the asphalt mixture. It was found that the largest ratio between the deformation occurring within the first hour and the total annual deformation was only approximately $5 \%$, which proved that it is feasible to neglect the deformation within the first hour when evaluating the high-temperature properties of materials using the temperature rutting rate.

However, the conditions of rutting tests are different from those of an actual asphalt pavement in terms of the driving conditions, air temperature, and pavement structure. The field survey conducted 
by Huang et al., [22] states that the predicted annual rut depth was 20 times greater than that in the actual pavement conditions. Thus, further coefficient correction is required to accurately predict the rut depth when using a temperature rutting rate.

\subsection{Correction of Rut Depth}

\subsubsection{Correction of Wheel Track Distribution}

Since the previously calculated rut depths considered all loading axles to be in the same track, which was not consistent with the lateral distribution of the wheel track, it is necessary to consider this particularity while determining the temperature rutting rate. The width of a one-way driving lane is $3.75 \mathrm{~m}$. Half this pavement width, $1.875 \mathrm{~m}$, was taken for the calculation in this study. The wheel tracks were assumed to be symmetrically distributed on both sides of the pavement. The investigation showed that the distribution of wheel tracks in the middle of the pavement presented a peak value and decreases along both sides of pavement cross-section. Thus, in this study, the lateral distribution of wheel tracks was assumed to be a sine curve, which can be expressed as:

$$
y=\frac{\pi \sin (\pi x / 1.875)}{3.75}
$$

where $y$ represents the wheel trace distribution coefficient, and $x$ represents the distance of a point from the center of the pavement.

Most of the times, the axle was located in the middle areas of the pavement, thereby causing a large rut depth. When the wheel width under the standard axle load was $0.302 \mathrm{~m}$, the position of one wheel width in the center half of the pavement was $x=0.7865-1.0885 \mathrm{~m}$. The coefficient of wheel trace distribution in this area can be calculated by the following equation:

$$
\int_{0.7865}^{1.0885} \frac{\pi \sin (\pi x / 1.875)}{3.75}=0.250188
$$

The coefficient of wheel trace distribution was found to be 0.25 , under the condition of standard axle load.

\subsubsection{Temperature Correction}

Based on the data recorded by the China Meteorological Network [23], Figure 8 depicts the variations in daily temperature in Beijing, when the daily maximum temperature was 15, 20, 30, and $35^{\circ} \mathrm{C}$. For example, when the daily maximum temperature is $30^{\circ} \mathrm{C}$, as shown in Figure 8 , it means that the temperature that day rises from the lowest night temperature of $14{ }^{\circ} \mathrm{C}$ to a peak of $30^{\circ} \mathrm{C}$ at noon. Equation (6) is used to predict the modified and unmodified rut depths and their ratios at the daily maximum temperature of $30^{\circ} \mathrm{C}$. These values are listed in Table 6 . 


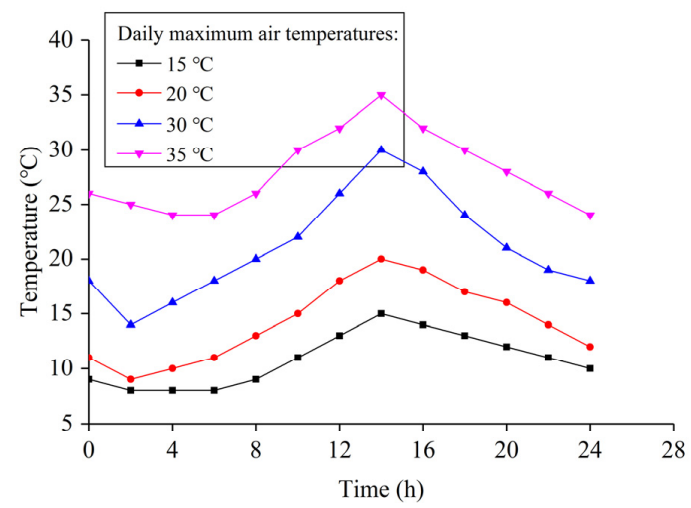

Figure 8. Daily variations of temperature for four different maximum temperatures.

Table 6. Prediction of modified and unmodified rut depths and their ratios.

\begin{tabular}{cccccc}
\hline $\begin{array}{c}\text { Diurnal Air } \\
\text { Temperature }\left({ }^{\circ} \mathbf{C}\right)\end{array}$ & Asphalt Mixture & $\begin{array}{c}\text { Temperature-Modified } \\
\text { Rut Depths }(\mathbf{m m})\end{array}$ & $\begin{array}{c}\text { Unmodified Rut } \\
\text { Depths }(\mathbf{m m})\end{array}$ & Ratio & $\begin{array}{c}\text { Mean } \\
\text { Value }\end{array}$ \\
\hline \multirow{3}{3}{30} & Matrix AC-16 & 0.66 & 0.96 & 0.69 & \\
& SMA-16 & 0.21 & 0.29 & 0.72 & 0.71 \\
& Modified AC-16 & 0.11 & 0.15 & 0.73 & \\
\hline
\end{tabular}

Similarly, the mean values of the ratios of the modified and unmodified rut depth were $0.86,0.72$, and 0.78 , corresponding to the daily maximum temperature of 15,20 , and $35^{\circ} \mathrm{C}$, respectively. The average value of the four results, 0.76 , was taken as the coefficient of temperature correction.

\subsubsection{Correction of Layer Thickness}

Yao et al. [24], found that the rutting resistance of the asphalt layer increases with its thickness. This study neglects the influence of structural layer change on the asphalt mixture and studies the influence of single-layer thickness on the rutting rate instead. Test molds, with 5 and $10 \mathrm{~cm}$ layer thickness, were used to conduct $4 \mathrm{~h}$ rutting tests on SMA-16 and modified AC-16 at four temperatures. The rutting rates were regressed and compared, as shown in Table 7.

Table 7. Rutting rate of asphalt mixture at different thickness (unit: $10^{-5} \mathrm{~mm} / \mathrm{load}$ times).

\begin{tabular}{|c|c|c|c|c|c|}
\hline $\begin{array}{l}\text { Asphalt } \\
\text { Mixture }\end{array}$ & $\begin{array}{c}\text { Test } \\
\text { Temperature } \\
\left({ }^{\circ} \mathrm{C}\right)\end{array}$ & $\begin{array}{c}\text { Rutting Rate of } \\
5 \mathrm{~cm} \text { Thickness } \\
\left(10^{-5} \mathrm{~mm} / \text { Load times }\right)\end{array}$ & $\begin{array}{c}\text { Rutting Rate of } \\
10 \mathrm{~cm} \text { Thickness } \\
\left(10^{-5} \mathrm{~mm} / \text { Load Times }\right)\end{array}$ & Ratio & $\begin{array}{l}\text { Mean } \\
\text { Value }\end{array}$ \\
\hline & 40 & 2.6 & 1.8 & 0.68 & \multirow{8}{*}{0.65} \\
\hline Modified & 50 & 4.0 & 2.9 & 0.72 & \\
\hline \multirow[t]{3}{*}{ AC- 16} & 60 & 6.1 & 3.3 & 0.54 & \\
\hline & 70 & 11.0 & 7.4 & 0.67 & \\
\hline & 40 & 4.6 & 2.9 & 0.63 & \\
\hline \multirow{3}{*}{ SMA-16 } & 50 & 6.1 & 3.5 & 0.58 & \\
\hline & 60 & 12.6 & 8.9 & 0.71 & \\
\hline & 70 & 16.0 & 11.2 & 0.70 & \\
\hline
\end{tabular}

It can be inferred from Table 7 that an increase in the single-layer thickness of asphalt mixture led to a significant decrease in the rutting rate of the mixture. This indicates that increasing the single asphalt layer thickness was conducive to the compaction of the mixture, thereby improving the overall strength of the pavement. A thickness of $5 \mathrm{~cm}$ was not optimal for the determination of the rutting resistance of the asphalt mixture by the conventional rutting test. Therefore, a pavement with a thickness of $10 \mathrm{~cm}$ was used in this study. The ratio of the rutting rate generated by asphalt layers of 10 and $5 \mathrm{~cm}$ was 0.65 ; this was used as the correction coefficient of the layer thickness in order to correct the rutting depth. 


\subsubsection{Correction of Driving Speed}

The stress time of the asphalt layer increased as the driving speed decreased, resulting in a longer creep compression time, which can generate larger rut depth $[25,26]$. The loading rate of the rutting test was $0.756 \mathrm{~km} / \mathrm{h}$, which was significantly less than the normal driving speed. Based on the prediction model of the creep rate, Hua [27] established the function between the ratio of rut depth and loading rate. The conversion coefficient of driving speed $K_{v}$ is defined as the ratio of rut depth, under the same loading times, of different loading rates and the reference loading speed of $20 \mathrm{~km} / \mathrm{h}$. It is expressed as follows:

$$
K_{v}=\frac{H_{v}}{H_{20}}=\left(\frac{v}{20}\right)^{-(m+1)}
$$

where $H_{v}$ is the rut depth at a certain driving speed $v(\mathrm{~km} / \mathrm{h}), H_{20}$ is the rut depth at the driving speed of $20 \mathrm{~km} / \mathrm{h}$, and $m$ is a material parameter, generally taken as -0.5 .

In this study, the driving speed of general urban pavements is considered to be $40 \mathrm{~km} / \mathrm{h}$, as obtained from relevant statistics. Using Equation (8), the ratio of rut depths, generated at the same loading times, at loading rates of $40 \mathrm{~km} / \mathrm{h}$ and $0.756 \mathrm{~km} / \mathrm{h}$ was 0.14 . Thus, the correction coefficient of driving speed was 0.14 .

$$
K_{v}=\frac{H_{v}}{H_{0.756}}=\frac{H_{v}}{H_{20}} \times \frac{H_{20}}{H_{0.756}}=\left(\frac{40}{20}\right)^{-0.5} \times \frac{1}{5.1}=0.14
$$

\subsection{Calculation of Modified Rut Depth}

As shown in Equation (9), the annual rut depth produced by the asphalt mixtures was modified according to four factors: wheel track distribution, temperature, thickness of asphalt layer, and loading rate.

$$
\varepsilon_{m}=\alpha \times a_{1} \times a_{2} \times a_{3} \times a_{4}
$$

where $\varepsilon_{m}$ is the modified rut depth; $\alpha$ is the unmodified rut depth are $\alpha_{1}, \alpha_{2}, \alpha_{3}$ and $\alpha_{4}$ the correction coefficients of wheel track distribution, temperature, layer thickness, and driving speed, respectively. Their values were $0.25,0.76,0.65$, and 0.14 , respectively.

Technical Specifications for Maintenance of Highway Asphalt Pavement [28] stipulates that when the rut depth is more than $15 \mathrm{~mm}$, it is considered to produce rut diseases. The modified rut depth and service lives of pavement materials were calculated by using Equation (9) and presented in Table 8.

Table 8. Modified annual rut depths and service lives of three asphalt mixtures.

\begin{tabular}{ccccccc}
\hline \multirow{2}{*}{ Asphalt Mixture } & \multicolumn{3}{c}{ Beijing } & \multicolumn{3}{c}{ Guangzhou } \\
\cline { 2 - 7 } & $\varepsilon \mathbf{c}(\mathbf{m m})$ & $\varepsilon_{\boldsymbol{m}} \mathbf{( m m )}$ & $\boldsymbol{T}^{\prime}(\mathbf{y})$ & $\varepsilon \mathbf{c}(\mathbf{m m})$ & $\left.\varepsilon_{\boldsymbol{m}} \mathbf{( m m}\right)$ & $\boldsymbol{T}^{\prime}(\mathbf{y})$ \\
\hline Matrix AC-16 & 231.72 & 5.96 & 2.52 & 368.04 & 6.36 & 3.36 \\
SMA & 71.31 & 1.23 & 12.20 & 108.27 & 1.87 & 8.02 \\
Modified AC-16 & 37.76 & 0.65 & 23.08 & 57.79 & 1.00 & 15.00 \\
\hline
\end{tabular}

The modified rut depth values illustrate that matrix AC-16 had the largest rutting depth among the three asphalt mixtures. However, SMA-16 and modified AC-16 could resist high-temperature rut better than matrix AC-16. Employing the temperature rutting rate to calculate rut depth was optimal because it simulated the actual situation and directly reflected the ability of asphalt mixtures to resist high-temperature rut. When combining the proposed evaluation system with the local climate and environment, the resistance of asphalt mixture to high temperatures could be successfully determined in different regions. However, its accuracy was directly affected by the accuracy of the four correction coefficients. Thus, the temperature and driving conditions should be extensively investigated to improve the prediction accuracy. 


\section{Conclusions}

In this study, a rutting test was performed for a long duration $(4 \mathrm{~h})$ on three typical asphalt mixtures, namely, matrix AC-16, SMA-16, and modified AC-16 asphalt mixtures, at four temperatures $\left(40,50,60\right.$, and $\left.70^{\circ} \mathrm{C}\right)$. A new index was proposed for the high-temperature performance evaluation of the asphalt mixture, after considering the air temperature and traffic volume of two different climatic regions. This index was termed as the temperature rutting rate. Finally, the annual rutting depth was calculated after considering the temperature rutting rate and the influence of wheel track distribution, temperature, thickness of the asphalt layer, and loading rate. The following conclusions were drawn from the study:

- The temperature rutting rate utilizes the rutting deformation data from hour 1-4 of the rutting test, during which the asphalt mixture is in a stable creep period. It also considers the climatic conditions. The temperature rutting rate is found to be more suitable than the traditional dynamic stability index as the index of high-temperature performance of the asphalt mixture.

- A comparison of the three asphalt mixtures reveals that the modified AC-16 asphalt mixture exhibits the least temperature rutting rate. Moreover, the introduction of the two additives (anti-rutting agent and lignin fiber) to the asphalt mixture significantly improves its high-temperature rut-resistance. Thus, this new asphalt mixture possesses good prospects for promotion and can adapt to a wider climatic area.

- To better simulate actual pavement conditions, multiple factors are considered in the modification of the rut depth, including wheel track distribution, temperature, pavement thickness, and loading rate. Finally, an ideal annual rutting depth generated by three asphalt materials is predicted. In addition, the reliability of the temperature rutting rate in predicting the rutting depth is directly related to the accuracy of the four correction coefficients.

Author Contributions: Methodology, Y.M. and Z.F.; writing-original draft, Y.M., Z.F., J.L., C.L., W.D., and J.D.; writing-review and editing, Y.M. and Z.F. All authors have read and agreed to the published version of the manuscript.

Funding: The project was supported by National Key R\&D Program of China (Grant No. 2018YFB1600200) and the Special Fund for Basic Scientific Research of Central Colleges, Chang'an University (Grant No. 300102318208).

Conflicts of Interest: The authors declare that they have no conflict of interest.

\section{References}

1. Zhang, Z.Q.; Tao, J.; Yang, B. Research on design parameter for high temperature performance of asphalt mixture. China J. Highw. Transp. 2009, 1, 23-28.

2. Anderson, R.M. Relationship between Superpave Gyratory Compaction Properties and the Rutting Potential of Asphalt Mixtures; Association Asphalt Paving Technologists: St Paul, MN, USA, 2002; pp. 207-247.

3. Zheng, C.F.; Wang, L.; Xu, Y.Z. Evaluation of High Temperature Stability of Asphalt Mixtures by Whole Process Dynamic Stability. J. Chongqing Jiao Tong Univ. (Nat. Sci.) 2011, 29, 51-55.

4. Kim, K.W.; Amirkhanian, S.N.; Kim, H.H.; Lee, M.; Doh, Y. A New Static Strength Test for Characterization of Rutting of Dense-Graded Asphalt Mixtures. J. Test. Eval. 2011, 39, 59-68.

5. Ziari, H.; Divandari, H.; Behbahani, H.; Ameri, M. Developing a Forecasting Model for Asphalt Rutting Potential Using Gyratory Compactor Parameters. Life Sci. J.-Acta Zhengzhou Univ. Overseas Ed. 2012, 9, 4140-4149.

6. Wen, H.F.; Bhusal, S. A Laboratory Study to Predict the Rutting and Fatigue Behavior of Asphalt Concrete Using the Indirect Tensile Test. J. Test. Eval. 2013, 41, 299-304. [CrossRef]

7. Ji, X.; Zheng, N.; Hou, Y.; Niu, S. Application of asphalt mixture shear strength to evaluate pavement rutting with accelerated loading facility (ALF). Constr. Build. Mater. 2013, 41, 1-8. [CrossRef]

8. Hafeez, I.; Kamal, M.A. Creep Compliance: A Parameter to Predict Rut Performance of Asphalt Binders and Mixtures. Arab. J. Sci. Eng. 2014, 39, 5971-5978. [CrossRef] 
9. Laukkanen, O.V.; Soenen, H.; Pellinen, T.; Heyrman, S.; Lemoine, G. Creep-Recovery behavior of bituminous binders and its relation to asphalt mixture rutting. Mater. Struct. 2014, 48, 1-15. [CrossRef]

10. Narayan, S.P.A.; Little, D.N.; Rajagopal, K.R. Analysis of Rutting Prediction Criteria Using a Nonlinear Viscoelastic Model. J. Mater. Civ. Eng. 2015, 27, 10.

11. Zhu, T.Y.; Ma, T.; Huang, X.M. Evaluating the rutting resistance of asphalt mixtures using a simplified triaxial repeated load test. Constr. Build. Mater. 2016, 116, 72-78. [CrossRef]

12. Liu, W.Q.; Liu, X.; Wang, Z.R. High temperature deformation investigation of asphalt mixture with nanosized volcanic ash fillers using optical fiber sensor. Measurement 2019, 171, 181. [CrossRef]

13. Dong, N.Y.; Ni, F.J.; Zhou, L. Comparison of the Hamburg, indirect tensile, and multi-sequenced repeated load tests for evaluation of hma rutting resistance. Constr. Build. Mater. 2019, 216, 588-598. [CrossRef]

14. Khotbehsara, M.M.; Manaloa, A.; Aravinthana, T. Effect of elevated in-service temperature on the mechanical properties and microstructure of particulate-filled epoxy polymers. Polym. Degrad. Stab. 2019, 170, 108994. [CrossRef]

15. Ferdousa, W.; Manaloa, A.; Wong, H. Optimal design for epoxy polymer concrete based on mechanical properties and durability aspects. Constr. Build. Mater. 2020, 232, 117229. [CrossRef]

16. Liu, W.; Liu, X.; Wang, Z.; Zhou, Z. New Asphalt Concrete Rutting Resistance Evaluation Method Based on Repeated-Load Test. J. Mater. Civ. Eng. 2020, 32, 04019351. [CrossRef]

17. Wang, K. Study on Evaluation Index of High and Low Temperature Performance Based on Regular Test. Master's Thesis, Chang'an University, Xi'an, China, 2011. (In Chinese).

18. Research Institute of Highway of the Ministry of Transport. Technical Specifications for Construction of Highway Asphalt Pavements (JTG F40-2004); People's Communications Press: Beijing, China, 2005. (In Chinese)

19. Research Institute of Highway of the Ministry of Transport. Specifications and Test Methods of Bitumen and Bituminous Mixtures for Highway Engineering (JTG_E20-2011); People's Communications Press: Beijing, China, 2011.

20. Huber, A.G. Weather Database for the Superpave (Trademark) Mix Design System; Revised Edition; Databases; National Research Council: Washington, DC, USA, 1994.

21. Witczak, M.W.; Kaloush, K.; Pwllinen, T. Simple Performance Test for Superpave Mix Design; National Academy Press: Washington, WA, USA, 2002; pp. 6-13.

22. Huang, X.M.; Fan, Y.W.; Zhao, Y.L.; Yan, Q.L. Investigation and test of expressway asphalt pavement high temperature performance. J. Highw. Transp. Res. Dev. 2007, 24, 16-20.

23. China Meteorological Network. The Data Set of the Annual Value and Daily Value of the Ground in China (1981-2010) [EB/OL]. 28 August 2012. Available online: http://data.cma.cn/ (accessed on 31 May 2020).

24. Yao, Z.Y.; Zhou, L.J.; Shang, Q.S.; Guo, J.M.; Wang, N. Analysis of Rutting Change Rule on Asphalt Pavement Overlay. Adv. Mater. Res. 2011, 368-373, 3131-3136. [CrossRef]

25. Xu, Y.; Guan, H.; Zhang, Q.; Zhou, L. The Rutting Resistant Surface Course Combination for Continuous Uphill Section of Expressway. In Proceedings of the GeoShanghai 2010 International Conference, Shanghai, China, 3-5 June 2010.

26. Ji, X.P.; Zheng, N.X.; Niu, S.S.; Wang, S.; Cong, Z.H. Study of Rutting Evaluation Criteria for Asphalt Mixture Based on ALF Test. China J. Highw. Transp. 2012, 23, 16-21.

27. Hua, J.F. Finite Element Modeling and Analysis of Accelerated Pavement Testing Devices and Rutting Phenomenon. Ph.D. Thesis, Purdue University, West Lafayette, IN, USA, 2000.

28. MOT (Ministry of Communications of the PRC). Technical Specifications for Maintenance of Highway Asphalt Pavement (JTJ073.2-2001); People's Communications Press: Beijing, China, 2001. (In Chinese)

(C) 2020 by the authors. Licensee MDPI, Basel, Switzerland. This article is an open access article distributed under the terms and conditions of the Creative Commons Attribution (CC BY) license (http://creativecommons.org/licenses/by/4.0/). 